\title{
Occupant response to different correlated colour temperatures of white LED lighting
}

\author{
Toftum, Jørn; Thorseth, Anders; Markvart, Jakob; Logadóttir, Ásta
}

Published in:

Building and Environment

Link to article, DOI:

10.1016/j.buildenv.2018.07.013

Publication date:

2018

Document Version

Peer reviewed version

Link back to DTU Orbit

Citation (APA):

Toftum, J., Thorseth, A., Markvart, J., \& Logadóttir, Á. (2018). Occupant response to different correlated colour temperatures of white LED lighting. Building and Environment, 143, 258-268.

https://doi.org/10.1016/j.buildenv.2018.07.013

\section{General rights}

Copyright and moral rights for the publications made accessible in the public portal are retained by the authors and/or other copyright owners and it is a condition of accessing publications that users recognise and abide by the legal requirements associated with these rights.

- Users may download and print one copy of any publication from the public portal for the purpose of private study or research.

- You may not further distribute the material or use it for any profit-making activity or commercial gain

- You may freely distribute the URL identifying the publication in the public portal 


\section{Accepted Manuscript}

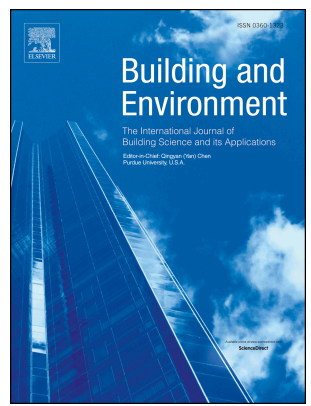

PII:

S0360-1323(18)30421-9

DOI:

10.1016/j.buildenv.2018.07.013

Reference: BAE 5573

To appear in: Building and Environment

Received Date: 12 April 2018

Revised Date: 29 June 2018

Accepted Date: 11 July 2018

Please cite this article as: Toftum Jø, Thorseth A, Markvart J, Logadóttir Á, Occupant response to different correlated colour temperatures of white LED lighting, Building and Environment (2018), doi: 10.1016/j.buildenv.2018.07.013.

This is a PDF file of an unedited manuscript that has been accepted for publication. As a service to our customers we are providing this early version of the manuscript. The manuscript will undergo copyediting, typesetting, and review of the resulting proof before it is published in its final form. Please note that during the production process errors may be discovered which could affect the content, and all legal disclaimers that apply to the journal pertain. 


\section{Occupant response to different correlated colour temperatures of white LED lighting}

Jørn Toftum ${ }^{1}$, Anders Thorseth ${ }^{2}$, Jakob Markvart ${ }^{3}$, Ásta Logadóttir ${ }^{3}$

${ }^{1}$ Department of Civil Engineering, Technical University of Denmark

${ }^{2}$ Department of Photonics, Technical University of Denmark

${ }^{3}$ Danish Building Research Institute, Aalborg University Copenhagen

Corresponding author:

Jørn Toftum

Technical University of Denmark

Nils Koppels Allé, building 402

2800 Lyngby

Denmark

Email: jt@byg.dtu.dk Ph.: +45 26282452 


\begin{abstract}
Correlated Colour Temperature (CCT) of lighting may affect not only occupant visual perception, but also other indoor environment perceptions, such as perceptions of the thermal environment or the air quality. This study aimed at quantifying the association between CCT of white LED lighting and subjective perceptions and performance at operative temperatures at the upper and lower borders and in the middle of the comfort range.
\end{abstract}

Higher CCT was significantly associated with decreasing thermal sensation, but only at the thermally neutral condition. Female subjects responded stronger to changes in CCT than male subjects. Under all temperature conditions, CCT was clearly associated with the perceived brightness of the light, and at $22^{\circ} \mathrm{C}$ also with the perceived air quality and with subjectively assessed alertness. CCT had no effect on the measured performance of a $\mathrm{d} 2$ task.

At $22^{\circ} \mathrm{C}$, the observed decrease in thermal sensation when CCT went from $2700 \mathrm{~K}$ to $6200 \mathrm{~K}$ was equivalent to a difference in operative of $1.7^{\circ} \mathrm{C}$. With an assumed neutral CCT of $4500 \mathrm{~K}$ (middle of range), a decreased heating set point in an office building, corresponding to an equivalent shift in CCT from $4500 \mathrm{~K}$ to $2700 \mathrm{~K}$, resulted in a reduction of around $8 \%$ of the building's total annual energy use. However, this assumes ideal conditions without influence from daylight, light from PC monitors, or coloured surfaces and other potentially disturbing factors.

\title{
Keywords
}

Indoor environment, illumination, thermal perception, lighting, temperature

\section{Introduction}

New LED technology that allows for control of illumination in terms of the CCT and illuminance intensity is currently being introduced widely in buildings. In addition to being energy efficient, LED lighting characteristics may affect both occupant visual perception and other subjective attributes of the indoor environment. However, knowledge on the influence on humans of interacting indoor environment exposures is not well established, although some studies did explore how humans reacted to simultaneous exposure to thermal factors, air quality, lighting, or noise [1-6].

One potential interaction is the association between colour and thermal sensation, which has been a recurrent research topic during almost a century [7-11]. These studies used a wide range of methods to expose subjects to different colour schemes without being able to document unambiguously an association with thermal sensation. Based on their experiments in which blue, red, and white colours were projected on a surface, Houghten et al. [8] speculated that a subject's psychological responses might affect his physiological responses to such an extent that he could be comfortable in a lower temperature because of the colour effect. However, Berry [9] did not find any change in the levels of heat subjects would tolerate as a function of the colours of illumination. Fanger et al. [10] exposed subjects to extreme blue at 150 lux and extreme red at 190 lux at two noise levels ( $40 \mathrm{dBA}$ and $85 \mathrm{dBA}$ ) and found that subjects preferred a slightly, but statistically significant, lower ambient temperature amounting to $0.4^{\circ} \mathrm{C}$ in the red than in the blue light. Greene and Bell [11] examined the possibility of wall colours mediating thermal comfort and found that colour influenced personal comfort and perceived environmental quality, but not the perceived 
temperature. The inconclusive findings of these early studies may be caused by different modes of exposure ranging from touching objects of different colour to rather extreme changes of the colour of the lighting $[7,10]$.

Recent studies that seem more relevant for modern lighting applications, and for the study reported in this article, provided similarly inconclusive results. Hübner et al. [12] found that thermal perception varied significantly between CCT at $2700 \mathrm{~K}$ and $6500 \mathrm{~K}$ when temperature was decreasing from $24^{\circ} \mathrm{C}$ to $20^{\circ} \mathrm{C}$, but not when the temperature was increasing in the same range. Despite challenges to control accurately the chamber temperature, this study supported the hypothesis that lighting characteristics may affect thermal perception and comfort. In addition, general acceptance of the chamber environment was the variable that most clearly and significantly depended on the CCT. In contrast, Baniya et al. [13] found no association between light source CCT and thermal sensation or comfort in their study in a test chamber with controllable LED lighting. In this study, subjects were exposed to three CCTs at $2700 \mathrm{~K}, 4000 \mathrm{~K}$, and $6200 \mathrm{~K}$ at two temperature levels of $20^{\circ} \mathrm{C}$ and $25^{\circ} \mathrm{C}$. In a simulated aircraft environment, Winzen et al. [14] exposed subjects to light at low illuminance (compared to an office setting) ranging from 124 lux to 223 lux and let the subjects fill in questionnaires on pocket PCs. Despite the potentially disturbing influence of light from the PC screens, the study found that the temperature perception was significantly lower in a room with blue light than in a room with yellow light. At the same time, the air was perceived as better and fresher in blue light and participants felt more alert than in yellow light. In a related study, Albers et al. [15] used a mock-up of an aircraft and found that lighting influenced subjective well-being.

In addition to perceptual responses, a range of physiological responses have also been associated with CCT or other colour characteristics of the environment. These include blood pressure [16], rectal temperature [17] melatonin suppression, attenuation of evening decline of core body temperature, and increased heart rate in light at $460 \mathrm{~nm}$ as compared with $550 \mathrm{~nm}$ [18]. It has also been suggested that light at low CCT may decrease central nervous system activity [19] and oppositely that very low-intensity blue light may increase objective alertness as measured by reaction time and EEG during prolonged nighttime performance testing [20]. In their comprehensive literature review, Souman et al. [21] noted that increasing the intensity of polychromatic white light increased subjective ratings of alertness, though a substantial portion of the studies failed to detect significant effects. Even fewer of the studies found significant effects of light on reaction time.

As was also concluded by te Kulve et al. [22] several studies indicate that lighting exposure may be able to alter subjective thermal sensation and comfort in controlled environment studies, although the effect has not been consistent between studies. Table 1 summarizes exposure modes and findings from the referenced studies on the association between colour and thermal perception.

\begin{tabular}{|l|c|c|c|c|}
\hline Study reference & Study location & Sample size & $\begin{array}{c}\text { Colour } \\
\text { applied to }\end{array}$ & $\begin{array}{c}\text { Effect of colour or } \\
\text { CCT on thermal } \\
\text { perception }\end{array}$ \\
\hline$[7]$ & Ohio, US & 25 & Objects & No \\
\hline$[8]$ & Pennsylvania, US & 2 & Screen & No \\
\hline$[9]$ & Virginia, US & 25 & Light & No \\
\hline$[10]$ & Lyngby, DK & 16 & Light & Yes \\
\hline$[11]$ & Colorado, US & 144 & Walls & No \\
\hline$[12]$ & London, UK & 32 & Light & Yes \\
\hline
\end{tabular}




\begin{tabular}{|l|c|c|c|c|}
\hline$[13]$ & Aalto, FI & 16 & Light & No \\
\hline$[14]$ & Hamburg, DE & 59 & Light & Yes \\
\hline$[15]$ & Göttingen, DE & 199 & Light & Yes \\
\hline$[23]$ & Kansas, US & 21 & Goggles & No \\
\hline
\end{tabular}

Table 1. Overview of exposure modes and outcomes of earlier studies dealing with the association between colour or CCT and thermal perception.

Four of the 10 studies included in Table 1 found an association between colour and thermal perception $[10,12,14,15]$. Common for these was that they used the CCT of the lighting as the main exposure variable. Only the study by Baniya et al. [13] did not find that CCT affected thermal sensation or comfort. Thus, although evidence in the literature is somewhat ambiguous, the referenced studies generally seem to support the hypothesis that visual stimuli, in addition to parameters related with the body's heat balance, may affect thermal perception. If the hypothesis is supported it may indicate that controllable LED lighting can expand the temperature interval that building occupants find comfortable and thereby reduce the use of energy to heat and cool buildings. Also, current literature suggests that other perceptual responses and performance-related metrics such as alertness may be influenced by the lighting in buildings, although the evidence is not entirely conclusive [21].

This study attempted to quantify the association between CCT of white LED lighting and subjective perceptions and performance at temperatures on the upper and lower boundary of the summer and winter thermal comfort envelopes, respectively, and at a temperature optimal for winter comfort. In addition, potential energy savings of the trade-off between adjustable LED lighting and heating set points were estimated.

\section{Methods}

Experiments were carried out with human subjects in a controlled environment chamber at the Technical University of Denmark (DTU). At constant room temperature, CCT was varied smoothly between plateaus at a rate that was designed to be imperceptible to the subjects. Indoor environment perceptions were assessed by questionnaires and the effect of the lighting exposure on subjects' performance was evaluated by a short standardized test.

\subsection{Experimental procedure}

When subjects arrived to an experimental session, they first acclimatized during $30 \mathrm{~min}$ in a room adjacent to the test room. The acclimatization room had a neutral temperature around $22^{\circ} \mathrm{C}$ and a CCT around 3500 $\mathrm{K}$. During the acclimatization period, they completed a questionnaire dealing with clothing composition, anthropometric data, whether they used glasses or contact lenses, were suffering from common symptoms like headache, blocked nose, irritated eyes, etc. They also indicated their sensitivity to high light intensity and low or high temperature on five-point scales going from not sensitive to extremely sensitive. Before each experiment, the subjects were told approximately what to wear to obtain a clothing insulation of 1 clo at $19^{\circ} \mathrm{C}$ and $22^{\circ} \mathrm{C}$ and $0.5 \mathrm{clo}$ at $27^{\circ} \mathrm{C}$. They also had to list their garments in the preliminary questionnaire and a picture was taken of their outfit the current day.

After acclimatization, subjects entered the test room and were seated at one of four desks. During the exposure period of $1.5 \mathrm{hrs}$ they completed six questionnaires and three $\mathrm{d} 2$ performance tests (Figure 1 ). The subjects had five minutes to answer a questionnaire and five minutes to complete the performance 
test. During these periods, the CCT was kept constant. Between questionnaires and performance tests, the subjects were entertained with newspapers and sudokus that were printed on eggshell coloured paper.

Figure 1 around here

\subsection{Subjects}

Forty-four paid subjects (16 female and 28 male) participated in the experiments. They were mostly students recruited by posters at the university and through social media. The aim was an equal gender distribution, but fewer female than male subjects signed up reflecting the gender composition at the university (Table 2). All subjects were from northern or central Europe, had normal eyesight and were not colour blind as documented with the Ishihara colour perception test [24]. Prior to their first experiment, subjects participated in an introduction session presenting the experimental procedure, the questionnaires and the performance test. Also, they were tested for colour blindness and instructed on which clothing to wear during the experiments at different temperatures. Subjects were told that the purpose of the study was to investigate the influence of the indoor environment on occupant perceptions and they were thus blind to the real purpose of the experiments.

All subjects participated in experiments at $19^{\circ} \mathrm{C}$ and $27^{\circ} \mathrm{C}$ (one subject did not show up under each of the two conditions) and half of them participated in the experiment at $22^{\circ} \mathrm{C}$. Three experimental sessions were conducted per day $(9-11,12-14,15-17)$ and a subject was assigned to only one time slot to minimize the influence of the circadian rhythm on the perception of the lighting. Table 2 shows anthropometric data of the subjects and how many took part in each of the three experimental conditions at $19^{\circ} \mathrm{C}, 22^{\circ} \mathrm{C}$ and $27^{\circ} \mathrm{C}$. All subjects gave their informed consent to participate in the experiments.

\begin{tabular}{|l|c|c|c|c|c|c|c|}
\hline & $\mathrm{N}_{\text {tot }}$ & Age (years) & Height $(\mathrm{m})$ & Weight $(\mathrm{kg})$ & $\mathrm{N}_{19}$ & $\mathrm{~N}_{22}$ & $\mathrm{~N}_{27}$ \\
\hline Female & 16 & $24.9(6.2)$ & $1.70(0.07)$ & $63.4(9.0)$ & 16 & 8 & 15 \\
\hline Male & 28 & $23.1(2.3)$ & $1.85(0.06)$ & $80.3(9.6)$ & 27 & 15 & 28 \\
\hline All & 44 & $23.8(4.2)$ & $1.79(0.10)$ & $75.2(12.4)$ & 43 & 23 & 43 \\
\hline
\end{tabular}

Table 2. Experimental participation and anthropometric data for the subjects. Numbers in parentheses indicate standard deviations.

\subsection{Experimental conditions}

In balanced order, subjects were exposed to CCTs that nominally varied from $2700 \mathrm{~K}$ to $6300 \mathrm{~K}$ and back to $2700 \mathrm{~K}$ or from $6300 \mathrm{~K}$ to $2700 \mathrm{~K}$ to $6300 \mathrm{~K}$. The lighting control solution Casambi was used to program the lighting animations from a Bluetooth connected application [25]. The application controlled a sequence of connected scenes with pre-defined CCT and lighting intensity. The lighting animations connected all the created scenes, fades and waits. Fade indicates the time it took to change from one scene to the next. The rate of change of CCT was adjusted according to the corresponding reciprocal colour temperature (RCT) to take into account the chromatic sensitivity of the human eye [26]. The procedure for composing the lighting animations was:

1. RCTs for all scenes were calculated

2. The RCT-difference between adjacent scenes was determined

3. Individual RCT-differences were divided with the sum of all RCT-differences to determine its relative magnitude 
4. The relative weights were multiplied with the total time allocated to non-steady CCT (total time subtracted wait time) to determine the time step between two levels of constant CCT

Waits were included at the minimum, lower quartile, median, upper quartile and maximum RCT. During waits, subjects completed questionnaires and performance tests.

Figure 2 shows the CCT schemes used during the experiments. The CCTs were measured after the lighting animations were set up in the lighting control system, but prior to carrying out the actual experiments. The luminous flux was adjusted so that the illuminance at desk level was around 1000 lux at all applied CCTs (Table 3). This illuminance was double that recommended for office settings [27], but was selected based on pre-tests to stimulate subjects' visual system to the degree possible without being too extreme and cause glare. Table 3 shows illuminance and corresponding Duv's for the luminaires measured after the lighting animations had been set up [28]. The measured CCTs did not span the entire range that the lighting specifications indicated for the applied fixtures and therefore cut-off points at around $2750 \mathrm{~K}$ and $6200 \mathrm{~K}$ were introduced in the lighting control system to facilitate reproducible lighting exposures between experiments.

Figure 2 around here

\begin{tabular}{|l|r|r|}
\hline $\begin{array}{c}\text { Nominal CCT } \\
\text { (K) }\end{array}$ & \multicolumn{1}{c|}{ Duv } & Illuminance (lux) \\
\hline 2700 & 0.0013 & 1021 \\
\hline 3000 & -0.0010 & 1058 \\
\hline 3600 & -0.0030 & 1052 \\
\hline 5000 & -0.0005 & 1063 \\
\hline 6300 & 0.0037 & 1067 \\
\hline
\end{tabular}

Table 3. Duv and illuminance measured at desk level for each nominal CCT after the lighting animations had been set up.

Figure 3 shows examples of the spectral distributions measured in the test room at the applied nominal CCTs.

Figure 3 around here

Exposures included three different operative temperatures at the lower boundary of the category $\mathrm{C}$ winter comfort envelope $\left(19^{\circ} \mathrm{C}\right)$, at the winter comfort temperature $\left(22^{\circ} \mathrm{C}\right)$, and at the upper boundary of the category $\mathrm{C}$ summer comfort envelope $\left(27^{\circ} \mathrm{C}\right)[29]$.

\subsection{Test room and lighting setup}

Experiments were carried out in a test room without daylight access and with the capacity to hold up to four subjects. The lighting system in the room comprised nine fixtures mounted in the suspended ceiling at the locations shown in Figure 4. Five of these were square fixtures (Philips RC464B LED80S/TWH PSD W60L60 VPC PIP) used to illuminate mostly the area occupied by the subjects and four rectangular fixtures (Philips RC464B LED80S/TWH PSD W30L120 VPC W) illuminated the wall in front of the subjects. These are essentially the same luminaire that differed only in shape. The fixtures contained cold-white and warmwhite LEDs that could be dimmed separately to achieve the desired CCTs.

Figure 4 around here 
The three walls in front and to the side of the subjects were covered with painted gypsum boards to ensure uniform spectral properties. The wall behind the subjects was painted brick, the floor a light gray lowpolluting floor covering material (polyolefine) and the ceiling consisted of modular, acoustical ceiling tiles. Table 4 shows the measured average spectral reflectance of the major surfaces in the room. These were measured prior to the experiments with a spectroreflectometer based on an Avantes C3648 spectrometer, a $\varnothing 50 \mathrm{~mm}$ integrating sphere and a halogen light source.

\begin{tabular}{|l|l|c|}
\hline Surface & Colour & Reflectance [\%] \\
\hline Walls (including door) & White & 88 \\
\hline Ceiling & White & 84 \\
\hline Floor & Gray & 38 \\
\hline Tables & White & 83 \\
\hline
\end{tabular}

Table 4. Average reflectance of the major surfaces in the test room.

Luminance images were captured with a TechnoTeam LMK Mobile prior to experiments and Figure 5 shows the luminance distribution as seen from the position at the second desk from left in Figure 4 . All four subject locations had rather uniform and almost similar luminance distributions around $250-300 \mathrm{~cd} / \mathrm{m}^{2}$ at desk level and between 125 and $250 \mathrm{~cd} / \mathrm{m}^{2}$ on the walls. The luminaires were mounted in the suspended ceiling and were clearly visible to the subjects, although their main field of vision included mostly the wall in front of them or the desks.

Figure 5 around here

The mechanical ventilation system that supplied air through the diffuse ceiling also controlled the room temperature. The ventilation rate was kept constant during all experiments at $92 \mathrm{~L} / \mathrm{s}$ corresponding to an air change rate of $8.3 \mathrm{~h}^{-1}$. Room dimensions were $5.65 \times 2.70 \times 2.60 \mathrm{~m}^{3}$.

\section{Physical measurements}

Before and during each experimental session a series of measurements were carried out to monitor the exposure conditions in the test room.

During the experiments, a SIM-2 spectral irradiance meter logged the lighting characteristics at $2 \mathrm{~s}$ intervals [30]. The instrument measured illuminance and the spectral power distribution of the irradiance from 380 to $780 \mathrm{~nm}$. From the spectral power distribution, chromaticity coordinates, colour rendering index, and CCT were calculated. Prior to starting an experiment, measurements were made on the working plane to validate an illuminance of 1000 lux regardless of the CCT. During the experiments, the instrument was fixed at a position approximately $0.5 \mathrm{~m}$ below the square lighting fixture in the corner (marked with $\mathrm{x}$ in Figure 4).

Operative temperature, relative humidity, and air velocity were measured with the Vivo measurement system from Dantec Dynamics [31] The Vivo Draught $20 T 31$ transducer measures air velocity and air temperature (range $0-1 \mathrm{~m} / \mathrm{s}, 0-40^{\circ} \mathrm{C}$; accuracy $\pm 2 \%$ ), the Vivo Temperature $20 \mathrm{~T} 32$ transducer measures operative temperature (range $0-60^{\circ} \mathrm{C}$; accuracy $\pm 0.03{ }^{\circ} \mathrm{C}$ ), and the Vivo Humidity $20 \mathrm{~T} 33$ transducer measures air humidity and temperature (range $0-100 \%, 0-45^{\circ} \mathrm{C} ; \pm 1 \%, \pm 0.03^{\circ} \mathrm{C}$ ). The surface temperatures in the room were measured with an Elma 610A Infrared Thermometer (range $-50-550^{\circ} \mathrm{C}$; accuracy $\pm 1.0 \% \pm 1.0^{\circ} \mathrm{C}$ in the $20-300^{\circ} \mathrm{C}$ range).

All Vivo transducers and the Elma 610A Infrared Thermometer were used before the beginning of an experiment to evaluate the possible difference in the thermal exposure between subjects. At each subject's 
position, the Vivo transducers were used at $0.1 \mathrm{~m}, 0.6 \mathrm{~m}$ and $1.1 \mathrm{~m}$ above the floor, corresponding to the ankle, abdomen and neck level of a seated person [32]. In the unoccupied room four heated dummies, each emitting $70 \mathrm{~W}$ to represent sensible human heat loss, were used during the pre-exposure measurements (Figure 4). During the experiments, the operative temperature and the humidity were logged at $1 \mathrm{~min}$ intervals at the center of the room $0.6 \mathrm{~m}$ above the floor.

The carbon dioxide concentration was measured with a Vaisala $\mathrm{CO}_{2}$ transducer model GMW22 (range 0 $5000 \mathrm{ppm}$; accuracy \pm ( $2 \%$ of the range $+2 \%$ of the reading)). The device was placed in head height on the wall behind the subjects and it logged the $\mathrm{CO}_{2}$ concentration at 5-minute intervals.

\subsection{Subjective measurements}

Subjects were asked to complete six identical questionnaires each containing 19 questions. The questionnaire focused on the subjects' perception of the thermal- and visual environment, but also questions about the air quality and the noise level were included, in part to blur the purpose of the study. An excerpt of the scales that were included in the questionnaire is included as supplementary material.

Questionnaires were printed on egg-shell coloured paper not to interfere with the subjects' visual adaptation.

Subjects were presented to three performance tests to measure their concentration ability [33]. The test consisted of 14 rows of the characters $d$ and $p$ with one or two dashes above and/or below each character. The task was to mark as many of the target characters as possible; the target character being a character $d$ with two dashes either above or below or one above and one below. A row should be completed in maximum 20 seconds.

\subsection{Data processing and analysis}

For each exposure, environmental data was aggregated for the periods with waits. Questionnaire responses were manually converted to spreadsheet format and then re-checked for consistency.

The $\mathrm{d} 2$ concentration performance was calculated as the number of correctly marked $\mathrm{d} 2$ characters subtracted the number of distracting characters marked mistakenly; the numbers were totaled across all 14 rows.

We used mixed effects modeling (MEM) to enable inclusion of both fixed effects and random factors (subjects) in the analysis (e.g. [34]). Associations between CCT and subject perceptions recorded on interval scales, e.g. thermal sensation, were thus analyzed with subject as random factor and CCT and gender as main effects and a term for the interaction between CCT and gender. The analysis was adjusted for covariates including clothing insulation and measured mean operative temperature during the relevant waits. Even though subjects acclimatized for $30 \mathrm{~min}$ at a resting condition prior to the experimental exposure, a slight decrease in their mean thermal sensation during the experiment was observed. To adjust for this, time ( 0 to $90 \mathrm{~min}$ ) was included as a covariate in the model. This did not affect if an independent variable was significant or not, but improved the log-likelihood of the tested mixed effects models. The model included both random intercepts at subject level and random coefficients accounting for differences in the effect of the CCT between subjects. Normality of residuals was checked in q-q plots

We used generalized estimating equations (GEE) in the analysis of data recorded on ordinal, categorical scales to account for intra-subject correlation (e.g. [35]). Associations between CCT and perceptions with more than two response categories were analyzed in Gaussian GEEs with identity link functions, also 
adjusted for the effect of covariates, which for thermal preference included time in all analyses, measured operative temperature and observed clothing insulation as well as the $\mathrm{CO}_{2}$ concentration in the analysis of the perceived air quality. Binary responses (fatigue and headache excluding don't know responses (See supplementary material) were also analyzed in GEEs, assuming a binomial distribution and logistic link function. All models used an exchangeable covariance structure to account for intra-subject correlation between questionnaires.

Based on subjects' indication of their sensitivity to high or low temperature or high light intensity, dummy variables were introduced with value 0 for those who answered they were not or only slightly sensitive and 1 for those who answered they were sensitive, very sensitive or extremely sensitive. This variable was used in generalized linear mixed effects models to test if subjects' sensitivity affected their thermal sensation, preferred temperature or perceived brightness of the light.

Generalized linear mixed effects models were used to test associations between CCT and the d2 concentration performance. The order of appearance when a subject had been presented to a test (1-6 for subjects participating in only two experimental sessions and 1-9 for the rest) was included in the model to adjust for learning effects. The model also accounted for autocorrelation between the order of appearance (learning) by estimating distinct variances for each within-group error. All analyses were carried out with Stata IC version 12.0 (Statacorp, TX, USA).

\section{Results}

\subsection{Environmental exposures}

Table 5 shows that the nominal and measured CCTs were very similar, although the standard deviation increased with the CCT. The CCT variability did not depend on the temperature and Table 5 therefore includes measurements made under all temperature conditions

\begin{tabular}{|l|l|}
\hline Nominal CCT (K) & $\begin{array}{l}\text { Measured CCT (K) } \\
\text { (mean } \pm \text { sd) }\end{array}$ \\
\hline 2700 & $2746 \pm 3$ \\
\hline 3000 & $2986 \pm 4$ \\
\hline 3600 & $3560 \pm 8$ \\
\hline 5000 & $4955 \pm 23$ \\
\hline 6300 & $6231 \pm 31$ \\
\hline
\end{tabular}

Table 5. Nominal and measured CCT. sd indicates standard deviation of measurements repeated at fixed lighting settings under all temperature conditions.

Figure 6 compares the operative temperatures measured in each experimental session with the corresponding nominal temperature. In most experiments, the operative temperature increased slightly from the beginning of the experiment before stabilizing after 15-20 min exposure. In general, however, the temperature increase from beginning to end of the experiments was rather modest.

Figure 6 around here

Table 6 summarizes all environmental parameters across experimental sessions at each nominal temperature. As Figure 6 also indicated, the measured and the nominal temperatures deviated only little, which was an important requirement for the evaluation of the expected modest effect of CCT on subjects' thermal responses. The clothing insulation was almost the same in the experiments at $19^{\circ} \mathrm{C}$ and $22^{\circ} \mathrm{C}$, but somewhat lower than the typical winter clothing insulation of $0.9-1 \mathrm{clo}$. At $27^{\circ} \mathrm{C}$, the mean clothing 
insulation matched fairly well the standard summer level of 0.5 clo. It was not possible to humidify or dehumidify the supply air, but despite variations of the outdoor temperature and thus outdoor air humidity, the relative air humidity in the test room decreased slightly with increasing temperature, indicating that the humidity ratio was rather constant (approximately $4-5 \mathrm{~g}$ vapour $/ \mathrm{kg}$ dry air). Due to the high air exchange rate needed to maintain a stable temperature, the $\mathrm{CO}_{2}$ concentration was generally low, although at $27^{\circ} \mathrm{C}$ it was slightly higher than at $19^{\circ} \mathrm{C}$ and $22^{\circ} \mathrm{C}$. The interior in the test room comprised lowpolluting materials, which, combined with a low $\mathrm{CO}_{2}$ concentration, should promote a good air quality.

The highest measured mean air velocity was $0.15 \mathrm{~m} / \mathrm{s}$, but mostly the mean air velocity was below $0.10 \mathrm{~m} / \mathrm{s}$ and spatially uniform. The background sound pressure level in the test room was around $48 \mathrm{~dB}(\mathrm{~A})$ regardless of the experimental condition.

\begin{tabular}{|l|c|c|c|}
\hline Nominal temperature & $19^{\circ} \mathrm{C}^{1)}$ & $22^{\circ} \mathrm{C}$ & $27^{\circ} \mathrm{C}$ \\
\hline Operative temperature $\left({ }^{\circ} \mathrm{C}\right)$ & $19.3 \pm 0.2$ & $22.1 \pm 0.2$ & $27.0 \pm 0.2$ \\
\hline Relative humidity $(\%)$ & $30 \pm 6$ & $28 \pm 4$ & $22 \pm 3$ \\
\hline Clothing insulation (clo) & $0.75 \pm 0.10$ & $0.76 \pm 0.06$ & $0.53 \pm 0.09$ \\
\hline $\begin{array}{l}\mathrm{CO}_{2} \text { concentration above } \\
\text { outdoors (ppm) }\end{array}$ & $167 \pm 54$ & $171 \pm 62$ & $240 \pm 98$ \\
\hline
\end{tabular}

${ }^{1)}$ Mean \pm standard deviation across experimental sessions at the listed nominal temperature

Table 6. Summary of environmental parameters measured in experiments at each nominal temperature.

\subsection{Associations between CCT and subjective perceptions}

Figure 7 shows that under all temperature conditions mean thermal sensation clearly depended on the operative temperature and approximated slightly cool at $19^{\circ} \mathrm{C}$, neutral at $22^{\circ} \mathrm{C}$, and slightly warm at $27^{\circ} \mathrm{C}$. Figure 7 also indicates that the crude association between CCT and the mean of the thermal sensation and the preferred temperature was rather weak. Thermal comfort varied with the temperature in a range between comfortable and slightly uncomfortable. The association between thermal sensation and thermal comfort did not depend on CCT. The air quality was perceived clearly better at $19^{\circ} \mathrm{C}$ than at $22^{\circ} \mathrm{C}$ or $27^{\circ} \mathrm{C}$ (Figure 8). Possibly due to the high illuminance of 1000 lux, the light was generally perceived as bright, but perceived brightness also increased with increasing $\mathrm{CCT}$, regardless of the operative temperature in the test room.

Figure 7 around here

Figure 8 around here

To monitor subjects' perceptions from the beginning of the exposure, they completed the first questionnaire immediately after being seated in the test room. Responses recorded with this questionnaire may therefore not reflect entirely the conditions in the room, as subjects likely were affected by the stepchange induced by the shift in environment from the acclimatization room to the test room. It was therefore decided to exclude responses recorded with this questionnaire from the statistical analyses of the association between CCT and subjective perceptions.

It is clear from Figure 7 that the temperature in the test room dominated the thermal sensation response as compared with the CCT. It was therefore also decided to carry out statistical analyses separately at each temperature level to minimize the confounding influence on the responses of the body's heat balance. 
Table 7 shows the results of the statistical modelling of thermal sensation, thermal preference, perceived air quality, and perceived brightness.

\begin{tabular}{|c|c|c|c|c|c|c|c|}
\hline & \multicolumn{2}{|c|}{$19^{\circ} \mathrm{C}$} & \multicolumn{2}{|c|}{$22^{\circ} \mathrm{C}$} & \multicolumn{2}{|c|}{$27^{\circ} \mathrm{C}$} & \multirow{2}{*}{$\begin{array}{l}\text { Model type } \\
\text { MEM }\end{array}$} \\
\hline hermal sensation & $\mathrm{p}$ & \begin{tabular}{|l|} 
Effect \\
size
\end{tabular} & $\mathrm{p}$ & $\begin{array}{l}\text { Effect } \\
\text { size }\end{array}$ & $\mathrm{p}$ & $\begin{array}{l}\text { Effect } \\
\text { size }\end{array}$ & \\
\hline CCT & 0.69 & $2.5 \cdot 10^{-5}$ & $<0.01 \downarrow$ & $-2.5 \cdot 10^{-4}$ & 0.78 & $1.3 \cdot 10^{-5}$ & \\
\hline Interaction CCT and gender* & 0.96 & $3.6 \cdot 10^{-6}$ & $<0.01$ & $2.4 \cdot 10^{-4}$ & 0.42 & $-4.5 \cdot 10-5$ & \\
\hline Gender** & 0.02 & 0.93 & 0.11 & -0.59 & 0.02 & 0.71 & \\
\hline Time & $0.01 \downarrow$ & $-5.5 \cdot 10^{-3}$ & $<0.01 \downarrow$ & $-8.7 \cdot 10^{-3}$ & $<0.01 \downarrow$ & $-5.2 \cdot 10-3$ & \\
\hline Measured operative temp. & 0.48 & -0.40 & 0.71 & 0.22 & $<0.01 \downarrow$ & -1.16 & \\
\hline Clothing insulation & 0.01 & 2.93 & 0.47 & -1.33 & 0.62 & 0.57 & \\
\hline hermal preference & & & & & & & GEE \\
\hline CCT & 0.65 & $-2.0 \cdot 10^{-5}$ & $0.01 \uparrow$ & $1.9 \cdot 10^{-4}$ & 0.86 & $8.2 \cdot 10^{-6}$ & \\
\hline Interaction CCT and gender* & 0.37 & $4.9 \cdot 10^{-5}$ & $<0.01$ & $-2.6 \cdot 10^{-4}$ & 0.96 & $2.6 \cdot 10^{-6}$ & \\
\hline Gender** & $<0.01$ & -1.13 & 0.29 & 0.47 & 0.04 & -0.65 & \\
\hline Time & $<0.01 \uparrow$ & $7.8 \cdot 10^{-3}$ & 0.09 & $5.2 \cdot 10^{-3}$ & 0.31 & $1.8 \cdot 10^{-3}$ & \\
\hline Measured operative temp. & 0.98 & -0.012 & 0.46 & 0.48 & 0.09 & 0.72 & \\
\hline Clothing insulation & $0.01 \downarrow$ & -2.69 & 0.0 .67 & 0.81 & 0.68 & 0.50 & \\
\hline erceived air quality & & & & & & & GEE \\
\hline CCT & 0.42 & $2.5 \cdot 10^{-5}$ & $<0.01 \uparrow$ & $1.2 \cdot 10^{-4}$ & 0.24 & $-3.7 \cdot 10^{-5}$ & \\
\hline Time & 0.54 & $1.2 \cdot 10^{-3}$ & $<0.01 \uparrow$ & $1.2 \cdot 10^{-2}$ & $<0.01 \uparrow$ & $6.7 \cdot 10-3$ & \\
\hline Measured $\mathrm{CO}_{2}$ & 0.48 & $2.1 \cdot 10^{-3}$ & 0.11 & $-3.8 \cdot 10^{-3}$ & 0.15 & $-1.6 \cdot 10^{-3}$ & \\
\hline erceived brightness & & & & 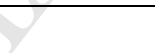 & & & MEM \\
\hline CCT & $<0.01 \uparrow$ & $1.6 \cdot 10^{-4}$ & $<0.01$ & $3.5 \cdot 10^{-4}$ & $<0.01 \uparrow$ & $1.8 \cdot 10^{-4}$ & \\
\hline Time & $<0.01 \downarrow$ & $-5.5 \cdot 10^{-3}$ & 0.07 & $-4.6 \cdot 10^{-3}$ & $<0.01 \downarrow$ & $-6.7 \cdot 10^{-3}$ & \\
\hline
\end{tabular}

$\downarrow$ means that dependent variable decreased with increasing independent variable $\uparrow$ means that dependent variable increased with increasing independent variable

* A significant outcome means that females' thermal sensation decreased more with increasing CCT than did males'.

** A significant outcome means that female subjects felt cooler than male subjects.

Table 7. Outcome in terms of significance levels ( $p$-values) and effect sizes of the statistical modelling of thermal sensation, thermal preference, perceived air quality and perceived brightness of the light.

Significant outcomes in bold.

Thermal sensation was significantly associated with CCT, but only at a temperature of $22^{\circ} \mathrm{C}$ where subjects felt cooler at the higher than at the lower CCT. This was contrary to expectations as at $19^{\circ} \mathrm{C}$ and $27^{\circ} \mathrm{C}$, on the edges of the temperature comfort zone, there was no association between thermal sensation and CCT. At $22^{\circ} \mathrm{C}$ the interaction between $\mathrm{CCT}$ and gender was significant indicating that females' thermal sensation decreased more with increasing CCT than did males'. Correspondingly, subjects preferred a higher temperature with increasing $\mathrm{CCT}$ at $22^{\circ} \mathrm{C}$, female subjects more so than male subjects.

At $22^{\circ} \mathrm{C}$, the air quality was perceived as being fresher at high than at low CCT, but as for thermal sensation, the temperature per se seemed to dominate the air quality response at $19^{\circ} \mathrm{C}$ and $27^{\circ} \mathrm{C}$. The strongest association with CCT was found for the perceived brightness, independent of the temperature in the test room, and subjects generally perceived the lighting as brighter the higher the CCT. Time from the start of the experiment was significantly associated with the dependent variable in most of the analyzed models, but as subjects were balanced between the $2700 \mathrm{~K}-6300 \mathrm{~K}-2700 \mathrm{~K}$ and the $6300 \mathrm{~K}-2700 \mathrm{~K}-6300 \mathrm{~K}$ exposure 
sequences, time was confounded with the CCT only at $3400 \mathrm{~K}$, which subjects always were exposed to during the second wait (Figure 2). Excluding this CCT from the analyses affected slightly the CCT effect magnitude, but not the significance level.

Grouping subjects according to their self-assessed sensitivity to low or high temperature or to high light intensity entailed that their distribution on the exposure sequences LHL and $\mathrm{HLH}$ was no longer balanced, but between $43 \% / 57 \%$ and up to $30 \% / 70 \%$. Also, only 23 subjects participated in the experiment at $22^{\circ} \mathrm{C}$ meaning that the subgroups at this temperature consisted of 7 sensitive and 16 non-sensitive subjects. Yet, at $22^{\circ} \mathrm{C}$ there was a weak tendency that subjects sensitive to low temperature responded stronger to the change in CCT than the non-sensitive ( $p=0.085$, MEM) and voted progressively cooler with increasing CCT. Likewise, those who were sensitive to high light intensity tended to prefer a higher temperature with increasing CCT ( $p=0.054, \mathrm{MEM})$. At $19^{\circ} \mathrm{C}$ and $27^{\circ} \mathrm{C}$, there was no relation between subjects' sensitivity to low temperature and CCT. Sensitivity to high temperature did not affect thermal sensation or temperature preference and sensitivity to high light intensity did not affect perceived brightness.

Subjects felt significantly more alert at high than at low CCT, but only at $22^{\circ} \mathrm{C}$ as shown in Table 8 . This did not affect the percentage of subjects feeling fatigue, which was independent of CCT. Also, alertness and fatigue were independent of the operative temperature. The percentage of subjects feeling headache increased significantly with $\mathrm{CCT}$ at all temperature levels (borderline at $22^{\circ} \mathrm{C}$ ) indicating that the subjects were negatively affected by the high CCTs. No association between the $\mathrm{d} 2$ concentration performance and the CCT was found.

\begin{tabular}{|l|l|l|l|l|l|l|l|}
\hline & \multicolumn{2}{|c|}{$19^{\circ} \mathrm{C}$} & \multicolumn{2}{c|}{$22^{\circ} \mathrm{C}$} & \multicolumn{2}{c|}{$27^{\circ} \mathrm{C}$} & Model type \\
\hline & $\mathrm{p}$ & $\begin{array}{l}\text { Effect } \\
\text { size }\end{array}$ & $\mathrm{p}$ & $\begin{array}{l}\text { Effect } \\
\text { size }\end{array}$ & $\mathrm{p}$ & $\begin{array}{l}\text { Effect } \\
\text { size }\end{array}$ & \\
\hline Alertness & & & & & & & GEE \\
\hline - CCT & 0.63 & $\mathbf{1 . 5 \cdot 1 0 ^ { - 5 }}$ & $<\mathbf{0 . 0 1 \uparrow}$ & $\mathbf{1 . 1 \cdot 1 0 ^ { - 4 }}$ & 0.44 & $2.6 \cdot 10^{-5}$ & \\
\hline - Time & $\mathbf{0 . 0 4} \downarrow$ & $\mathbf{- 3 . 6 \cdot 1 0 ^ { - 3 }}$ & 0.72 & $-8.1 \cdot 10^{-4}$ & 0.29 & $-2.0 \cdot 10^{-3}$ & \\
\hline Fatigue & & & & & & & GEE - logistic \\
\hline - CCT & 0.28 & $6.9 \cdot 10^{-5}$ & 0.08 & $1.4 \cdot 10^{-4}$ & 0.37 & $4.2 \cdot 10^{-5}$ & \\
\hline - Time & 0.08 & $-6.4 \cdot 10^{-3}$ & 0.13 & $6.7 \cdot 10^{-3}$ & 0.14 & $-3.9 \cdot 10^{-3}$ & \\
\hline Headache & & & & & & & GEE - logistic \\
\hline - CCT & $\mathbf{0 . 0 2} \uparrow$ & $-\mathbf{2 . 5 \cdot 1 0 ^ { - 4 }}$ & 0.05 & $1.7 \cdot 10^{-4}$ & $\mathbf{0 . 0 2} \uparrow$ & $\mathbf{- 2 . 0 \cdot 1 0 ^ { - 4 }}$ & \\
\hline - Time & 0.97 & $2.5 \cdot 10^{-4}$ & 0.23 & & $<\mathbf{0 . 0 1} \uparrow$ & $-1.4 \cdot 10^{-2}$ & \\
\hline
\end{tabular}

$\uparrow$ means higher alertness or higher percentage of subjects feeling fatigue or headache with increasing CCT or Time

$\downarrow$ means lower alertness or lower percentage of subjects feeling fatigue or headache with increasing CCT or Time

Table 8. Outcome of the statistical modelling in terms of significance levels ( $p$-values) and effect sizes of alertness, fatigue and headache. Significant outcomes in bold.

\section{Discussion}

As was also suggested by Houghten et al. (1940), we expected that CCT would influence thermal sensation mostly at temperatures on the boundaries of the comfort zone. This appeared to be a wrong assumption, as a significant effect of CCT on thermal sensation was seen only at $22^{\circ} \mathrm{C}$ in the middle of the winter comfort temperature range. This result is intriguing as potential modification of temperature set points in buildings by controlling CCT would probably be more relevant around optimal comfort than on the edge of the class $\mathrm{C}$ comfort zone corresponding to thermal sensations close to slightly cool and slightly warm [29]. 
Also, females felt colder than males at the same temperature and their thermal sensation seemed to decrease faster with increasing CCT. The experiments were designed to attain mean thermal sensations of \pm 0.7 and 0 on the seven point scale, but the outcome at the extreme temperatures was closer to -1.2 and 1.1 at $19^{\circ} \mathrm{C}$ and $27^{\circ} \mathrm{C}$, respectively. It seems that at these temperatures visual, stimuli could not compete with the overall body heat balance, which thus seemed to dominate subjects' thermal sensation responses. In correspondence with this, subjects generally preferred a slightly higher temperature at $19^{\circ} \mathrm{C}$ and a slightly lower temperature at $27^{\circ} \mathrm{C}$, regardless of the CCT. At $22^{\circ} \mathrm{C}$ the shift in thermal sensation caused by the CCT also induced a change in the preferred temperature. At $27^{\circ} \mathrm{C}$, thermal sensation decreased with increasing mean operative temperature, although the temperature varied only in a rather narrow interval between $26.5^{\circ} \mathrm{C}$ and $27.4^{\circ} \mathrm{C}$. It is likely that this unexpected finding was caused by a progressively decaying metabolic rate, which may have caused the subjects' thermal sensation to also decrease.

Perceived brightness increased significantly with the CCT and in general, this was the response that most clearly and consistently was affected by the CCT. This was in agreement with Laurentin et al. [36] and several of the studies included in the comprehensive literature review by Fotios et al [37], although some of the referenced studies also suggested that CCT was an insufficient metric for so-called spatial brightness. At $22^{\circ} \mathrm{C}$, the perceived air quality improved with increasing CCT, even though the measured air temperature, air humidity and $\mathrm{CO}_{2}$ concentration varied only little within this temperature condition. The perceived air quality differed more clearly between the three temperature conditions in the test room, confirming the influence of the air temperature on the perceived air quality [38-40]. Overall, these findings suggest that the different domains of the indoor environment interact to some degree, but that the strength of the interaction varies with the domain and the type of perceptual outcome. However, as the human sensory system integrates and processes a multitude of inputs, e.g. thermal, atmospheric, visual, and acoustic, future design of buildings and their technical systems should aim at accounting better for these interactions.

We purposely selected participants that were all from northern or central Europe with the purpose to minimize the influence of differences in CCT customs between the temperate to cold northern climate regions with a custom for "warmer" lighting and the warmer southern regions, where "colder" lighting seems to be more common. Therefore, the findings of this study are limited to people accustomed to lighting behaviors that may be more typical in temperate to northern climate regions.

Subjects who assessed themselves to be sensitive to temperature or light could possibly also be those who responded stronger to changes in CCT. However, this hypothesis could not be verified, although some indications of differences between the sensitive and non-sensitive subgroups were seen. As anticipated did the subjects who were sensitive to low temperature generally feel cooler and prefer higher temperature than the non-sensitive. However, the association between subjects' sensitivity to temperature and their response to changing CCT was not strong and never significant. Subjects were not recruited according to their sensitivity and in particular, the grouping into sensitive and non-sensitive resulted in rather small subgroups that were not balanced in relation to the sequence of CCT exposure. With the current study design, subjects' general sensitivity to indoor environment exposures could thus not explain the association between CCT and thermal responses.

A rather high illumination of 1000 lux at desk level was applied, which was higher than in most of the cited earlier studies that also detected effects of CCT on thermal responses (from 125 to 500 lux) [10,12,14,15]. Also, the general appearance of the test room was unusually clinical with large white surfaces, which, in combination with the illumination, was expected to best stimulate responses to the changing CCT. If no 
effect of CCT would be observed under these conditions, it is unlikely that more realistic conditions with lower illumination, daylight, and differently coloured surfaces would elicit a response. Despite the high illumination did subjects not note that the CCT was changing and they generally remained naïve to the purpose of and the exposure used in the experiments. The experimental conditions and thus the applied CCT levels were determined based on the RCT. As a consequence, subjects were only exposed to a CCT of $3400 \mathrm{~K}$ early in the experiments and not after different experimental durations, as was the purpose of exposing subjects to either the LHL or HLH sequences (Figure 2). This may have caused that subjective perceptions of the thermal environment, air quality and lighting deviated somewhat from the general trends at a CCT of $3400 \mathrm{~K}$.

Banyia et al. [13] speculated that if the effect of CCT on thermal sensation and comfort was real and persisted also outside well-controlled climate chambers, light source CCTs could be used to sustain energy savings in buildings. Correspondingly, Hübner et al. [12] suggested that the use of light to impact on comfort would be to reduce consumption of power in situations of high power demand. In this study and at an operative temperature of $22^{\circ} \mathrm{C}$, the association between CCT and thermal sensation was significant with an effect magnitude of -0.000992 (scale units)/(K CCT). This was estimated as an average of females and males and therefore the effect magnitude differs from Table 7 that includes also the interaction between gender and CCT. The average effect magnitude corresponds to a difference in mean thermal sensation of 0.35 scale units between the minimum and maximum CCT applied in the experiments. This difference in thermal sensation was converted to an equivalent difference in operative temperature using the PMV model with a metabolic rate typical for office work (1.2 met), standard winter clothing insulation (1 clo), a low air velocity $(0.1 \mathrm{~m} / \mathrm{s})$ and a relative humidity of $28 \%$ as recorded during the experiments (Table 6) [41]. Calculations were made with the Berkeley thermal comfort tool and showed that a CCT of $2750 \mathrm{~K}$ at $21.2^{\circ} \mathrm{C}$ should cause the same thermal sensation as a CCT of $6200 \mathrm{~K}$ at $22.9^{\circ} \mathrm{C}$ (Table 9) [42].

\begin{tabular}{|l|l|l|l|}
\hline PMV & 0.17 & 0 & -0.18 \\
\hline $\mathrm{CCT}(\mathrm{K})$ & 2750 & 4500 & 6200 \\
\hline $\mathrm{t}_{\mathrm{o}}\left({ }^{\circ} \mathrm{C}\right)$ & 21.2 & 22.0 & 22.9 \\
\hline
\end{tabular}

Table 9. Estimated difference in operative temperature equivalent to the observed difference in mean thermal sensation between the extremes of the applied CCTs. Average for females and males.

Changing CCT from $2700 \mathrm{~K}$ to $6200 \mathrm{~K}$ at a comfortable temperature thus resulted in an equivalent temperature difference of $1.7^{\circ} \mathrm{C}$, considerably larger than the difference in directly determined preferred temperature of $0.4^{\circ} \mathrm{C}$ as observed by Fanger et al. [10] when using red and blue light. In an attempt to quantify the potential energy savings of stimulating thermal sensation by use of CCT, we made a simple, dynamic simulation of a room in a typical Danish office building and used as a reference a heating set point temperature of $22^{\circ} \mathrm{C}$ at an assumed mid-range CCT of 4500K [43]. By changing the heating set point to $21.2^{\circ} \mathrm{C}$ at a CCT of $2750 \mathrm{~K}$ with an unchanged mean thermal sensation, a reduction of around $8 \%$ of the building's total annual energy use was found when the building was located in a cool temperate climate (Denmark). However, in practice this reduction in energy use will be smaller due to the influence of daylight, light from computer monitors, a more diverse colour scheme in offices, and the general uncertainty if the effect of CCT on thermal sensation will persist also during sustained periods of time.

Subjects felt more alert in high than in low CCT, but only at $22^{\circ} \mathrm{C}$. This was in agreement with Souman et al. [21] who reported that in a majority of their reviewed studies, polychromatic white light increased subjective alertness, although a substantial proportion of the studies for different reasons failed to document the effect. Mostly, the studies referenced by Souman et al. [21] reporting significant effects on subjective alertness of the CCT were carried out in the evening. Our exposures were limited to mornings or 
afternoons, as defined by Souman et al., when melatonin levels are low and CCT may be less likely to affect alertness. At $19^{\circ} \mathrm{C}$ and $27^{\circ} \mathrm{C}$, the percentage of subjects reporting headache increased with CCT. The higher self-reported alertness at $22^{\circ} \mathrm{C}$ in the current study was not reflected in the objectively measured performance, which was unaffected by the CCT.

In summary, the main finding of this study was that CCT was associated with thermal sensation, not at the border of the comfort zone as expected, but at a condition close to thermal neutrality. This finding relied on subject exposures in a rather clinical environment and with a high lighting intensity and therefore it may have statistical more than practical relevance. To estimate if the interaction between lighting characteristics and thermal sensation can be used in practice to save energy in buildings, further studies that include daylight, light from PC monitors and other disturbing effects should be carried out.

\section{Conclusions}

Carefully controlled experiments were carried out with human subjects exposed to CCT in a range that currently can be achieved with controllable, white LED lighting and at operative temperatures at the border of and in the middle of the comfort range.

CCT was associated with thermal sensation at the thermally neutral condition, but not when subjects felt slightly cool or slightly warm. The reason could be that the heat balance of the body dominated the thermal response when subjects were not feeling neutral. Female subjects responded stronger to changing CCT than male subjects. Also, there was a weak tendency that subjects who were sensitive to low temperature responded stronger to changes in the CCT.

CCT was clearly associated with the perceived brightness of the light, regardless of the applied operative temperature, and at $22^{\circ} \mathrm{C}$ also with the perceived air quality. At this temperature, the air was perceived as being fresher with increasing CCT.

At $22^{\circ} \mathrm{C}$, subjects felt more alert with increasing $\mathrm{CCT}$, but this did not affect their objective performance as measured with a standardized task.

An equivalent temperature difference of $1.7^{\circ} \mathrm{C}$ corresponding to the shift in thermal sensation when CCT went from $2750 \mathrm{~K}$ to $6200 \mathrm{~K}$ at a constant operative of $22^{\circ} \mathrm{C}$ was found. Shifting the heating set point in an office building by one-half of this difference, from a neutral CCT to the lowest CCT applied in this study, resulted in a reduction of around $8 \%$ of the building's total energy use. However, this simulation result assumed ideal conditions without considering influence from daylight, light from PC monitors, or coloured surfaces and other potentially disturbing factors.

\section{Acknowledgement}

Vibeke Christensen, Kasper Støttrup From, Michelle Kühl, Marie Rosenbeck, and Nanna Gudmandsen, all former students at the Technical University of Denmark, are acknowledged for their enormous contribution to the preparation and execution of the experiments. This study was supported financially by the ELFORSK research programme, project 348-030.

\section{References}

[1] Clausen, G., Carrick, L., Fanger, P.O., Kim, S.W., Poulsen, T., Rindel, J.H. (1993). A comparative study of discomfort caused by indoor air pollution, thermal load and noise. Indoor Air, 3(4):255-262. 
[2] Alm, O., Witterseh, T., Clausen, G., Toftum, J., Fanger, P.O. (1999). The impact of human perception of simultaneous exposure to thermal load, low-frequency ventilation noise and indoor air pollution.

Proceedings of the 8th International Conference on Indoor Air Quality and Climate, Edinburgh, Scotland; 5: 270-275.

[3] Toftum, J. (2002). Human response to combined indoor environment exposures. Energy and Buildings, 34(6), 601-606.

[4] Pellerin, N., Candas, V. (2003). Combined effects of temperature and noise on human discomfort. Physiol Behav, 78(1):99-106.

[5] Candas, V., Dufour, A. (2005). Thermal Comfort: Multisensory Interactions? Multisensory integration: Neurophysiological data. Journal of physiological anthropology and applied human science 24, 33-36.

[6] Frontczak, M., Wargocki, P. (2011). Literature survey on how different factors influence human comfort in indoor environments. Building and Environment, 46. 922-937.

[7] Mogensen, M. F., and English, H. B. (1926). The apparent warmth of colors. The American Journal of Psychology.

[8] Houghten, F.C., Olson, H.T., Suciu J. (1940). Sensation of warmth as affected by the color of the environment. Illuminating Engineering, vol. 35(10), 908-914.

[9] Berry, P., 1961. Effect of colored illumination upon perceived temperature. Journal of Applied Psychology, 45(4), 248-250.

[10] Fanger, P.O., Breum, N.O., Jerking, E. (1977). Can colour and noise influence man's thermal comfort. Ergonomics, 20(1), 11-18.

[11] Greene, T.C., Bell, P.A. (1980). Additional considerations concerning the effects of warm and cool wall colours on energy conservation. Ergonomics 23, 949-954. doi:10.1080/00140138008924804[12] Hübner, G.M., Shipworth, D.T., Gauthier, S., Witzel, C., Raynham, P. Chan, W. (2016). Saving energy with light? Experimental studies assessing the impact of colour temperature on thermal comfort. Energy Research and Social Science, 15, 45-57.

[13] Baniya, R. R., Tetri, E., Virtanen, J., Halonen, L. (2016). The effect of correlated colour temperature of lighting on thermal sensation and thermal comfort in a simulated indoor workplace. Indoor and Built Environment, 0(0), 1-9. https://doi.org/10.1177/1420326X16673214

[14] Winzen, J., Albers, F., \& Marggraf-Micheel, C. (2014). The influence of coloured light in the aircraft cabin on passenger thermal comfort. Lighting Research and Technology, 46(4), 465-475.

https://doi.org/10.1177/1477153513484028

[15] Albers, F., Maier, J., \& Marggraf-Micheel, C. (2015). In search of evidence for the hue-heat hypothesis in the aircraft cabin. Lighting Research \& Technology, 47(4), 483-494.

[16] Kobayashi, H., Sato, M. (1992). Physiological Responses to illuminance and color temperature of lighting. The Annals of physiological anthropology, 11(1), 45-49.

[17] Takakura, J. Y., Nishimura, T., Choi, D., Egashira, Y., Watanuki, S. (2015). Non-thermal sensory input and altered human thermoregulation: effects of visual information depicting hot or cold environments. International journal of biometeorology, 59(10), 1453-1460. 
[18] Cajochen, C., Münch, M., Kobialka, S., Kräuchi, K., Steiner, R., Oelhafen, P., Orgül, S., Wirz-Justice, A. (2005). High sensitivity of human melatonin, alertness, thermoregulation, and heart rate to short wavelength light. The Journal of Clinical Endocrinology \& Metabolism, 90(3), 1311-1316.

https://doi.org/10.1210/ic.2004-0957.

[19] Noguchi, H., Sakaguchi, T. (1999). Effect of Illuminance and Color Temperature on Lowering of Physiological Activity. Applied Human Science, 18(4), 117-123. https://doi.org/10.2114/jpa.18.117

[20] Phipps-Nelson, J., Redman, J. R., Schlangen, L. J. M., Rajaratnam, S. M. W. (2009). Blue light exposure reduces objective measures of sleepiness during prolonged nighttime performance testing. Chronobiology International, 26(5), 891-912. https://doi.org/10.1080/07420520903044364

[21] Souman, J. L., Tinga, A. M., te Pas, S. F., van Ee, R., \& Vlaskamp, B. N. (2017). Acute alerting effects of light: A systematic literature review. Behavioural brain research.

[22] te Kulve, M., Schellen, L., Schlangen, L. J. M., \& Marken Lichtenbelt, W. D. (2016). The influence of light on thermal responses. Acta Physiologica, 216(2), 163-185.[23] Bennett, C. A., Rey, P. (1972). What's so hot about red? Human Factors, 14(2), 149-154.

[24] Ishihara, S. (1918). Tests for Color Blindness. American Journal of Ophthalmology, 1(5), 376.

[25] Casambi (2016). Casambi Specification, Casambi Technologies Oy. Available at: https://casambi.com/static/datasheets/Specification.pdf

[26] Boyce, P.R. (2014). Human Factors in Lighting, $3^{\text {rd }}$ edition, CRC Press, Florida.

[27] DS/EN 12464-1 (2011). Light and lighting - Lighting of work places - Part 1. Indoor work places. CEN European Committee for Standardization. Brussels, Belgium.

[28] American National Standards Institute (2017). American national standard for electric lampsspecifications for the chromaticity of solid-state lighting products. Publication ANSI C78.377-2017. National Electrical Manufacturers Association, Rosslyn, Virginia.

[29] ISO 7730 (2005). Ergonomics of the thermal environment - Analytical determination and interpretation of thermal comfort using calculation of the PMV and PPD indices and local thermal comfort criteria. International Organization for Standardization, Geneva.

[30] Metrue 2014, SIM-2 Spectral Irradiance Meter, Metrue, Inc. Available from: http://metrue.com/product info.php?id=198 (accessed 2017-12-13).

[31] Dantec Dynamics (2017). Available at: http://www.dantecdynamics.com.

[32] ISO 7726 (1998). Ergonomics of the thermal environment - Instruments for measuring physical quantities. International Organization for Standardization, Geneva.[33] Brickenkamp, R. (2002). Test d2. Aufmerksamkeits- Belastungs-Test. Manual 9. ausgabe, Göttingen, Hogrefe Verlag.

[34] West, B.T., Welch, K.B., Galecki, A.T. (2015) Linear Mixed Models: A Practical Guide Using Statistical Software, 2 ed. CRC Press, Taylor and Francis Group, ISBN-13: 978-1-4665-6102-1 (440 pages)

[35] Hardin, J.W., Hilbe, J.M. (2013) Generalized estimating equations. Chapman \& Hall/CRC. ISBN-13: 9781-4398-8113-2 (277 pages) 
[36] Laurentin, C., Berrutto, V., Fontoynont, M. (2000). Effect of thermal conditions and light source type on visual comfort appraisal. International Journal of Lighting Research and Technology, 32(4), 223-233.

[37] Fotios, S., Atli, D., Cheal, C., Houser, K., \& Logadóttir, Á. (2015). Lamp spectrum and spatial brightness at photopic levels: A basis for developing a metric. Lighting Research \& Technology, 47(1), 80-102.

[38] Fang, L., Clausen, G., Fanger, P. O. (1998). Impact of temperature and humidity on the perception of indoor air quality. Indoor air, 8(2), 80-90.

[39] Fang, L., Clausen, G., Fanger, P. O. (1998). Impact of temperature and humidity on perception of indoor air quality during immediate and longer whole-body exposures. Indoor Air, 8(4), 276-284.

[40] Toftum, J., Jørgensen, A. S., Fanger, P. O. (1998). Upper limits of air humidity for preventing warm respiratory discomfort. Energy and Buildings, 28(1), 15-23.

[41] Fanger, P.O. (1970). Thermal comfort. Danish Technical Press, Copenhagen, Denmark.

[42] Hoyt, T., Schiavon, S., Piccioli, A., Cheung, T., Moon, D., \& Steinfeld, K. (2017). CBE Thermal Comfort Tool. Center for the Built Environment, University of California Berkeley, http://comfort.cbe.berkeley.edu/ (25-02-2018).

[43] IDA Indoor Climate and Energy, ver. 4.7. (2018). EQUA Simulation AB, Sweden. 


\section{ACCEPTED MANUSCRIPT}

Condition

$\begin{array}{lllllllllll}6300 \mathrm{~K}-2700 \mathrm{~K}-6300 \mathrm{~K} & 0 & 10 & 20 & 30 & 40 & 50 & 60 & 70 & 80 & 90 \mathrm{~min} \\ & \mathrm{Q} 1 & & \text { Q2 P1 } & \text { Q3 P2 } & \text { Q4 } & & \text { Q5 } & \text { Q6 P3 } & \end{array}$

$2700 \mathrm{~K}-6300 \mathrm{~K}-2700 \mathrm{~K}$

Q1 Q2 P1

Q3 P2

Q4

Q5 Q6 P3 


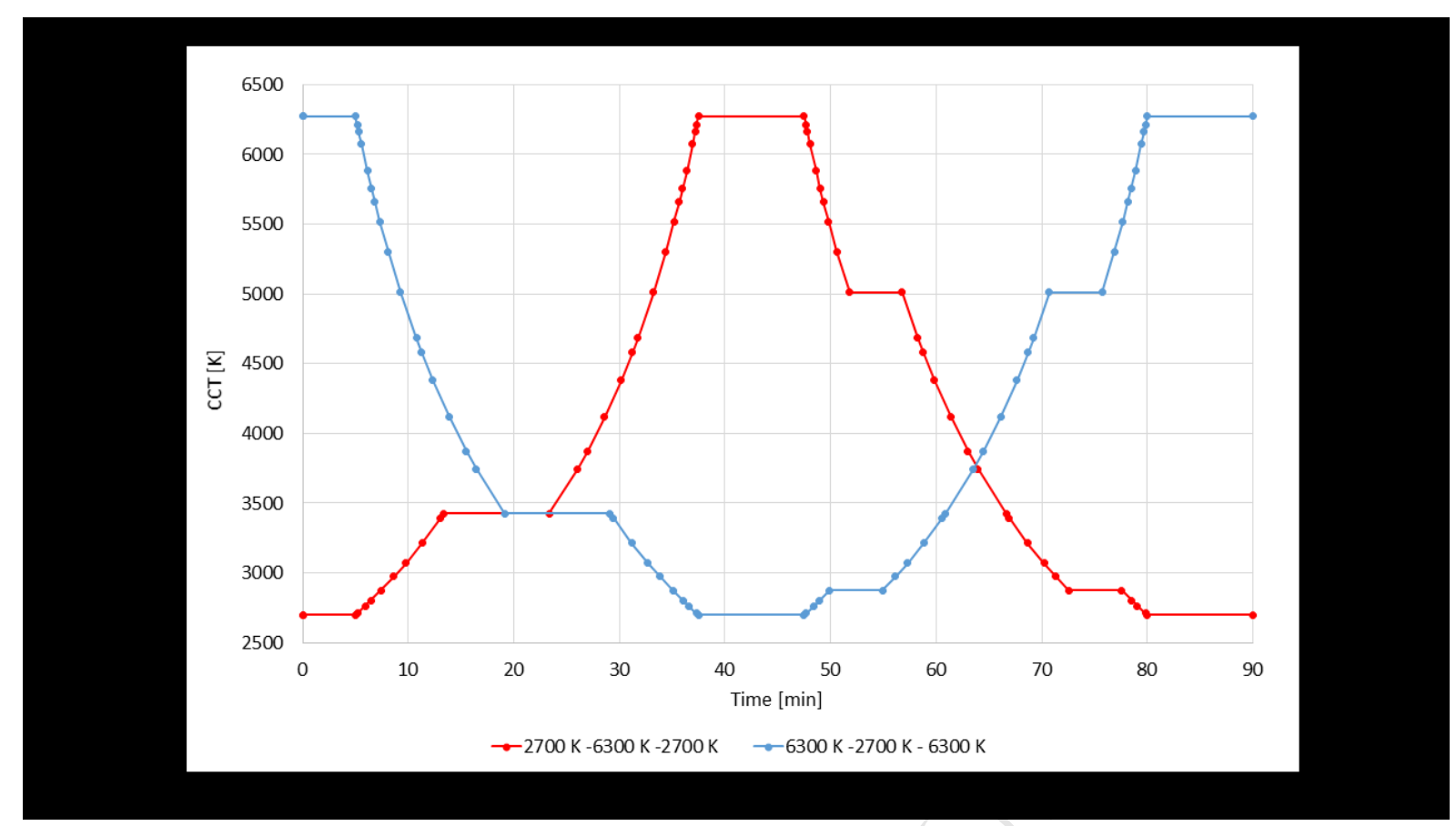




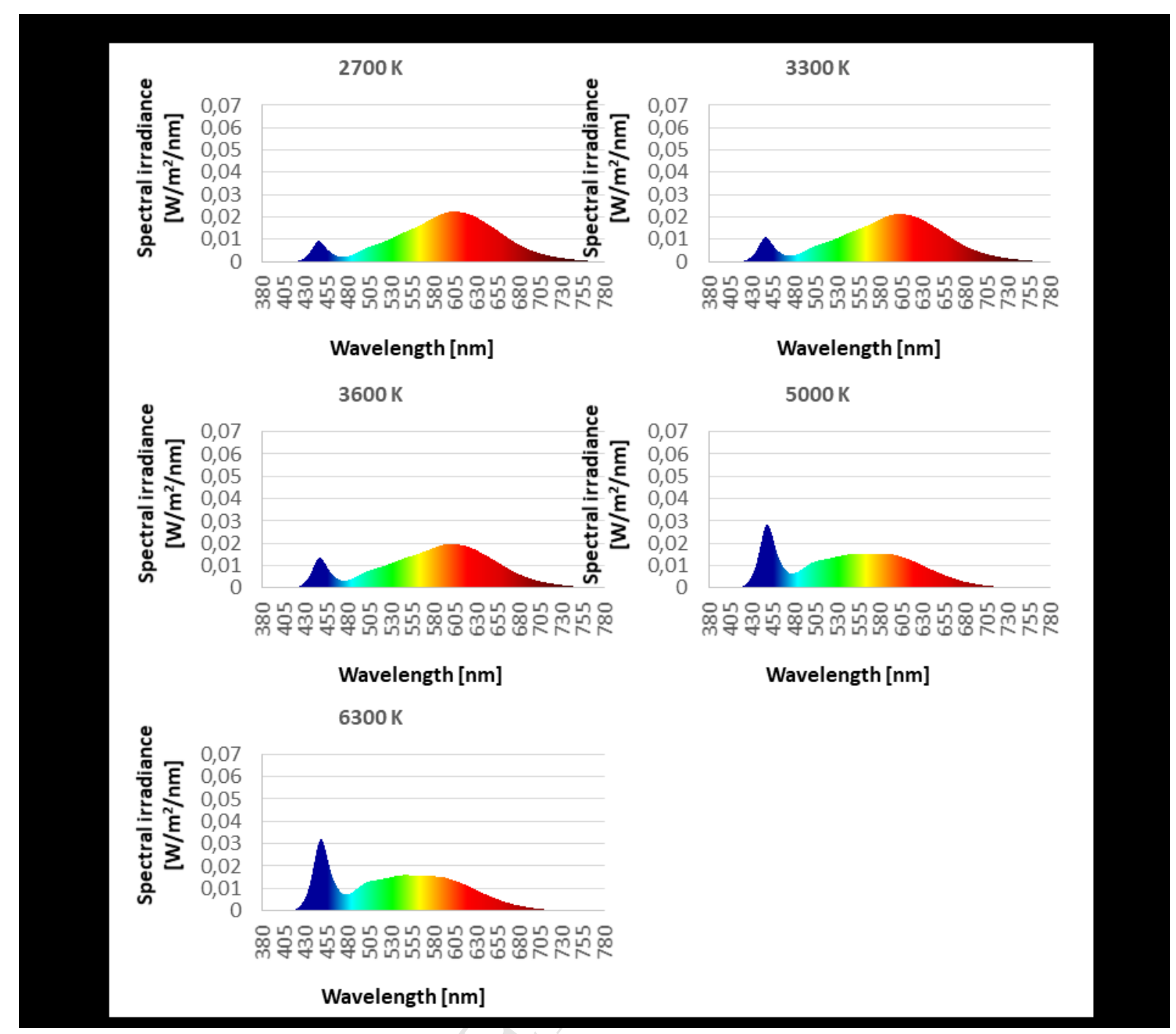




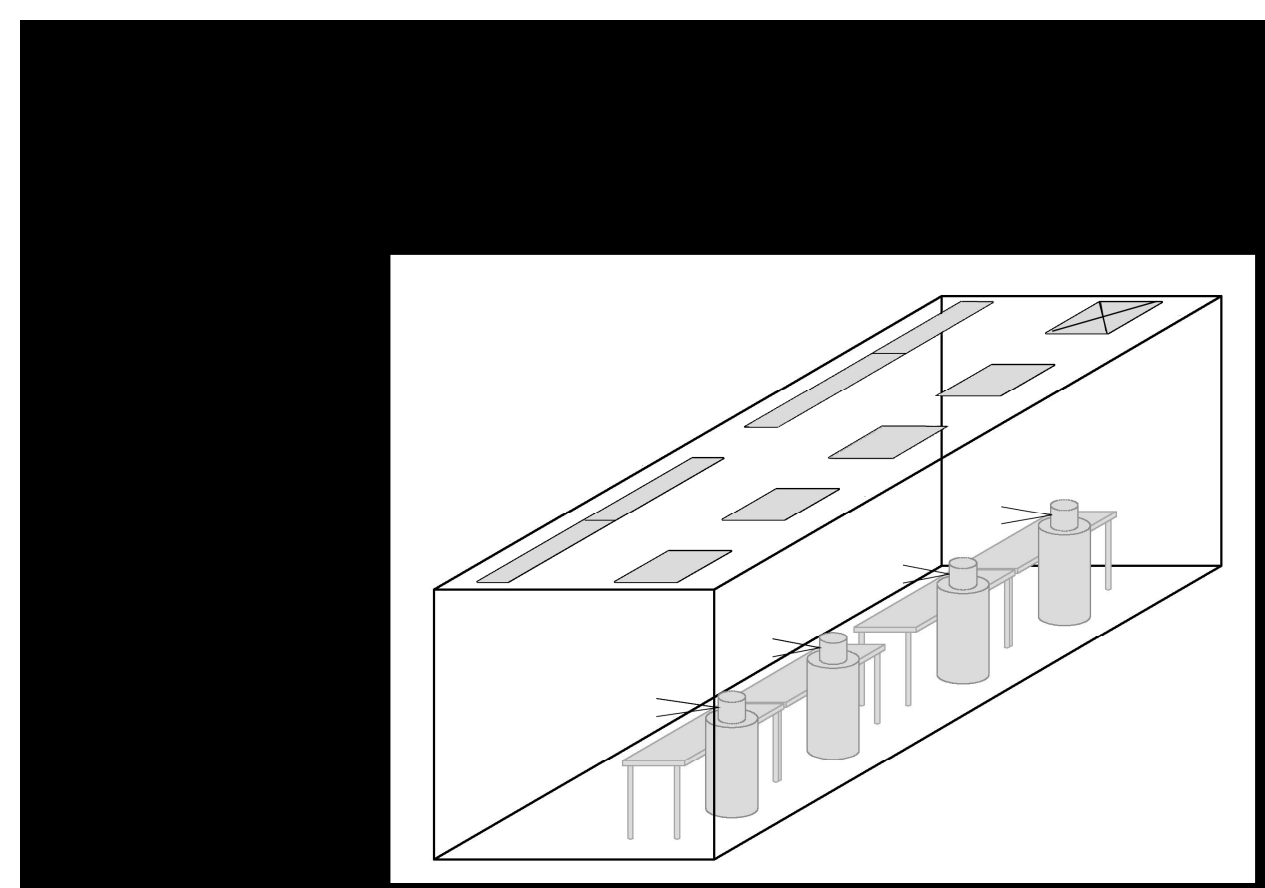




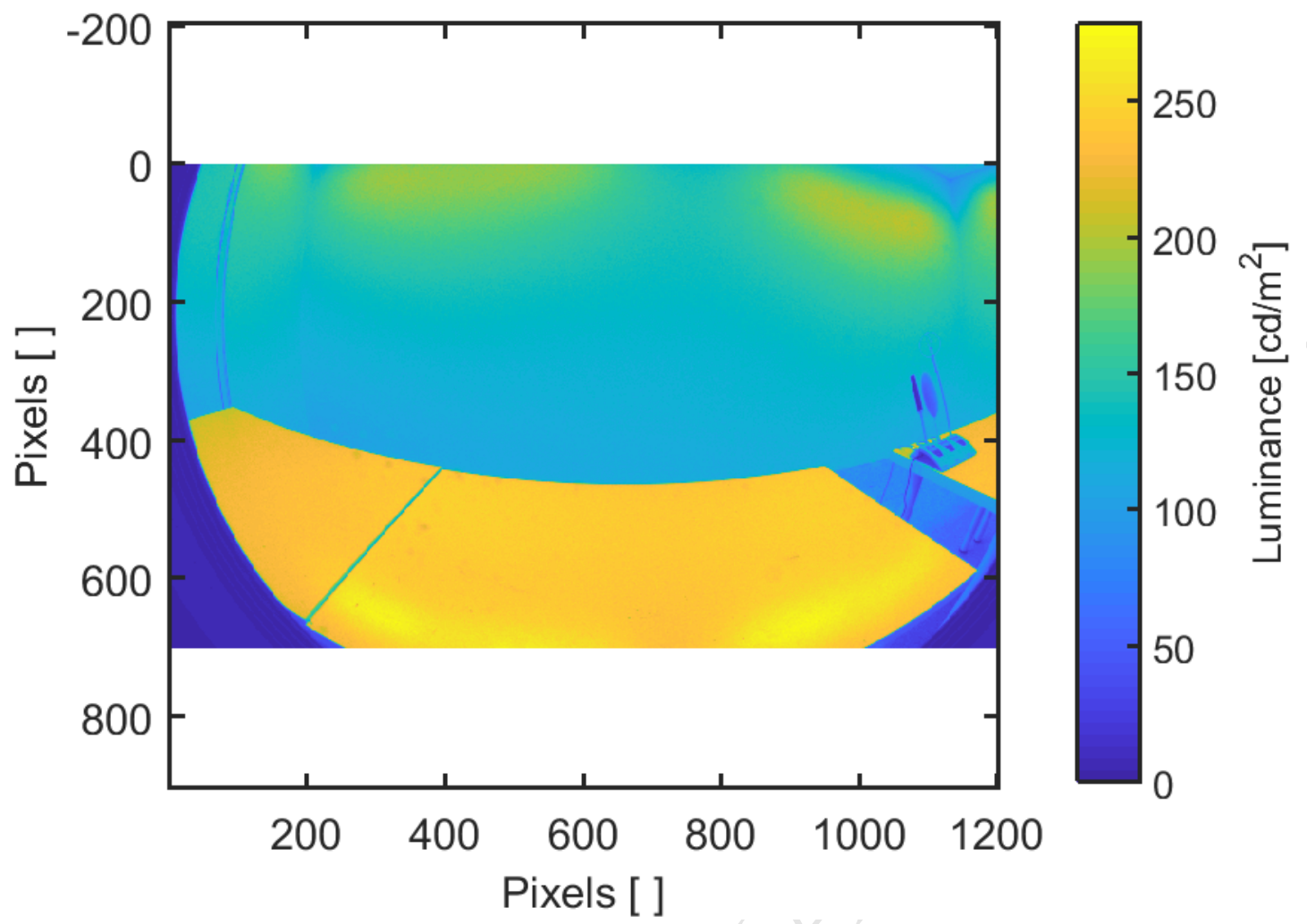


$19^{\circ} \mathrm{C}$

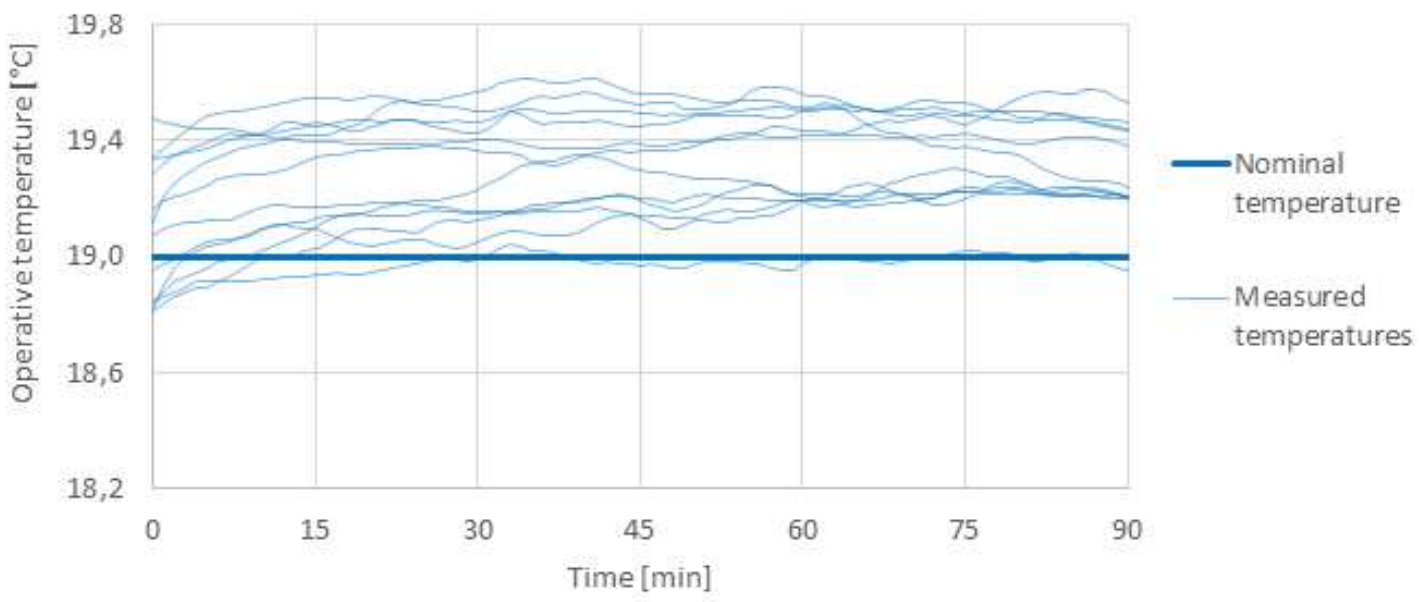

$22^{\circ} \mathrm{C}$

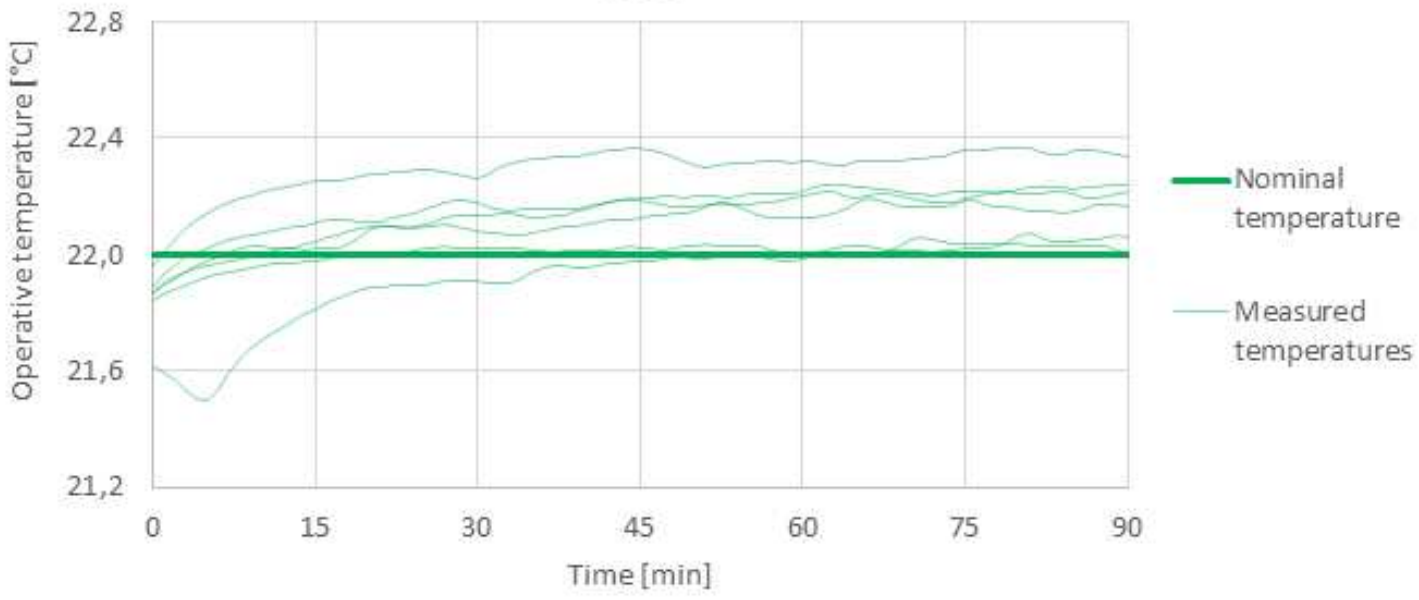

$27^{\circ} \mathrm{C}$

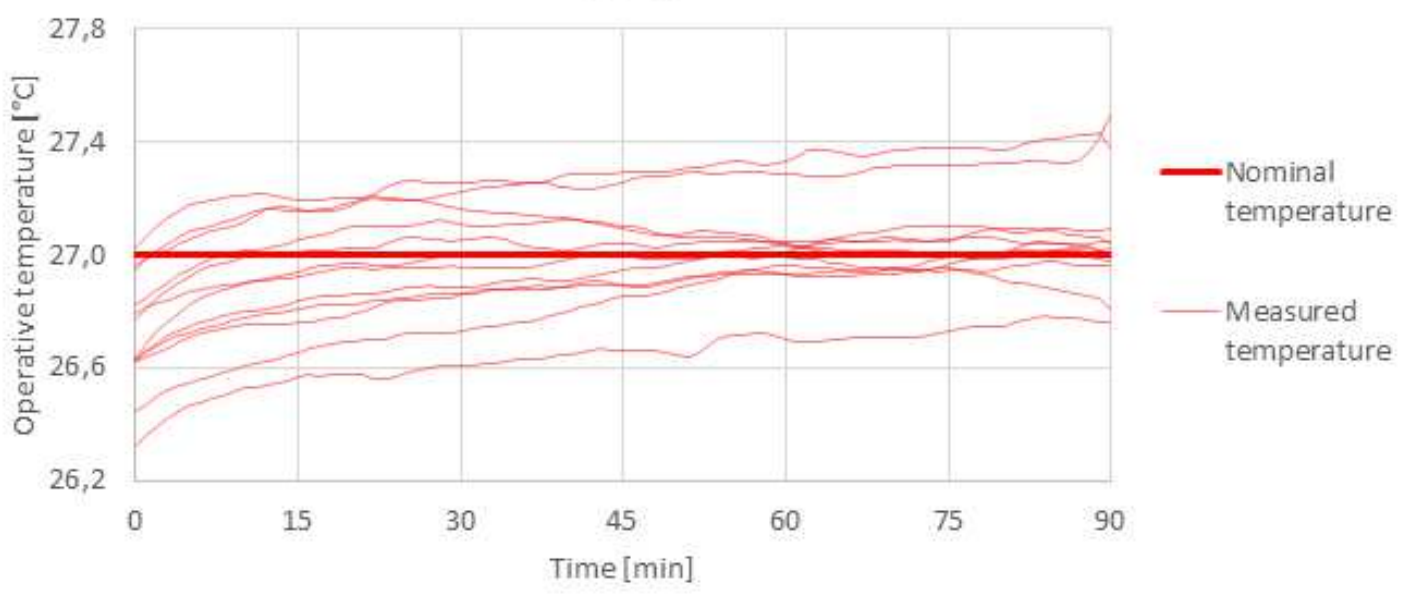




\section{ACCEPTED MANUSCRIPT}

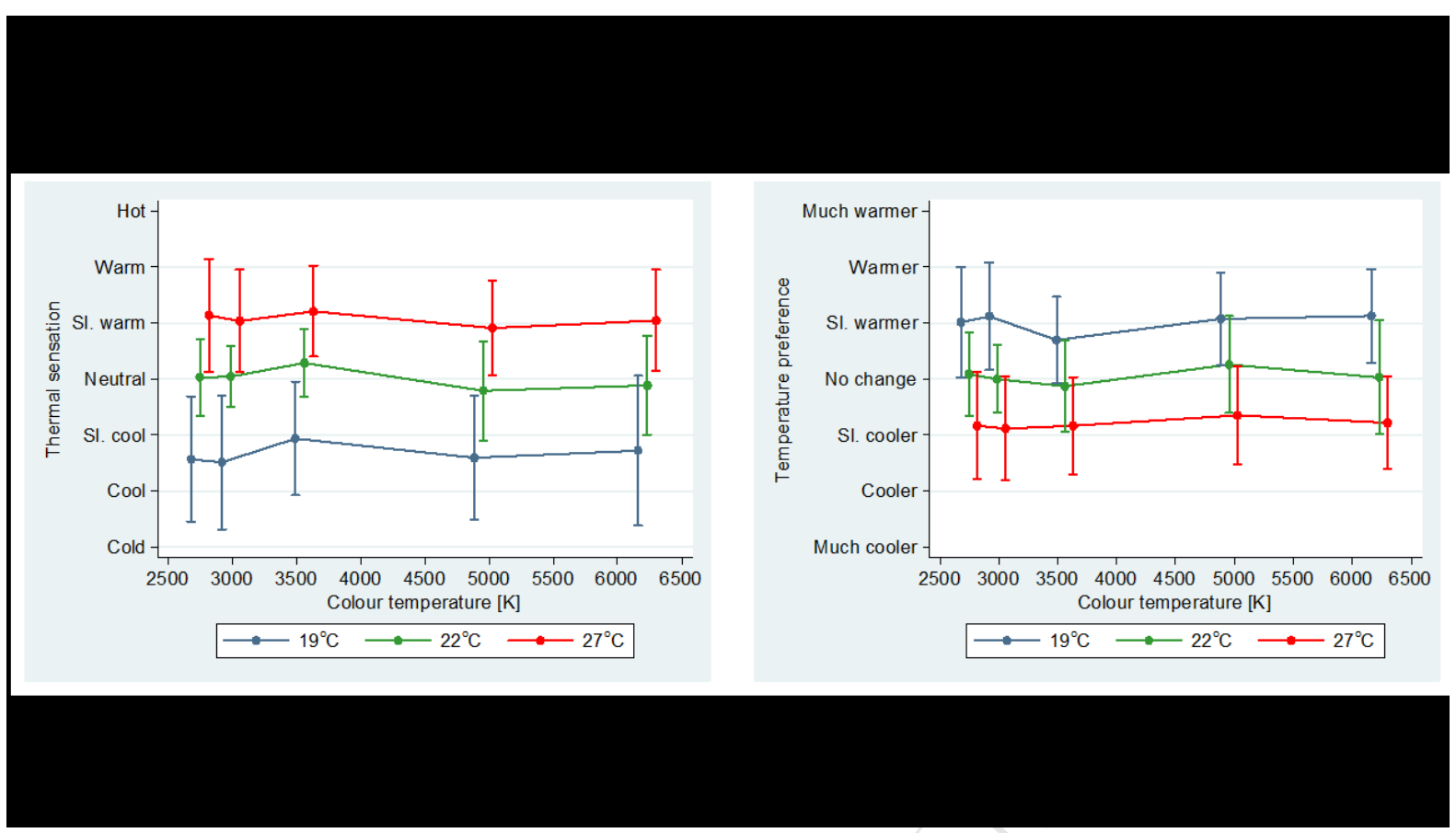




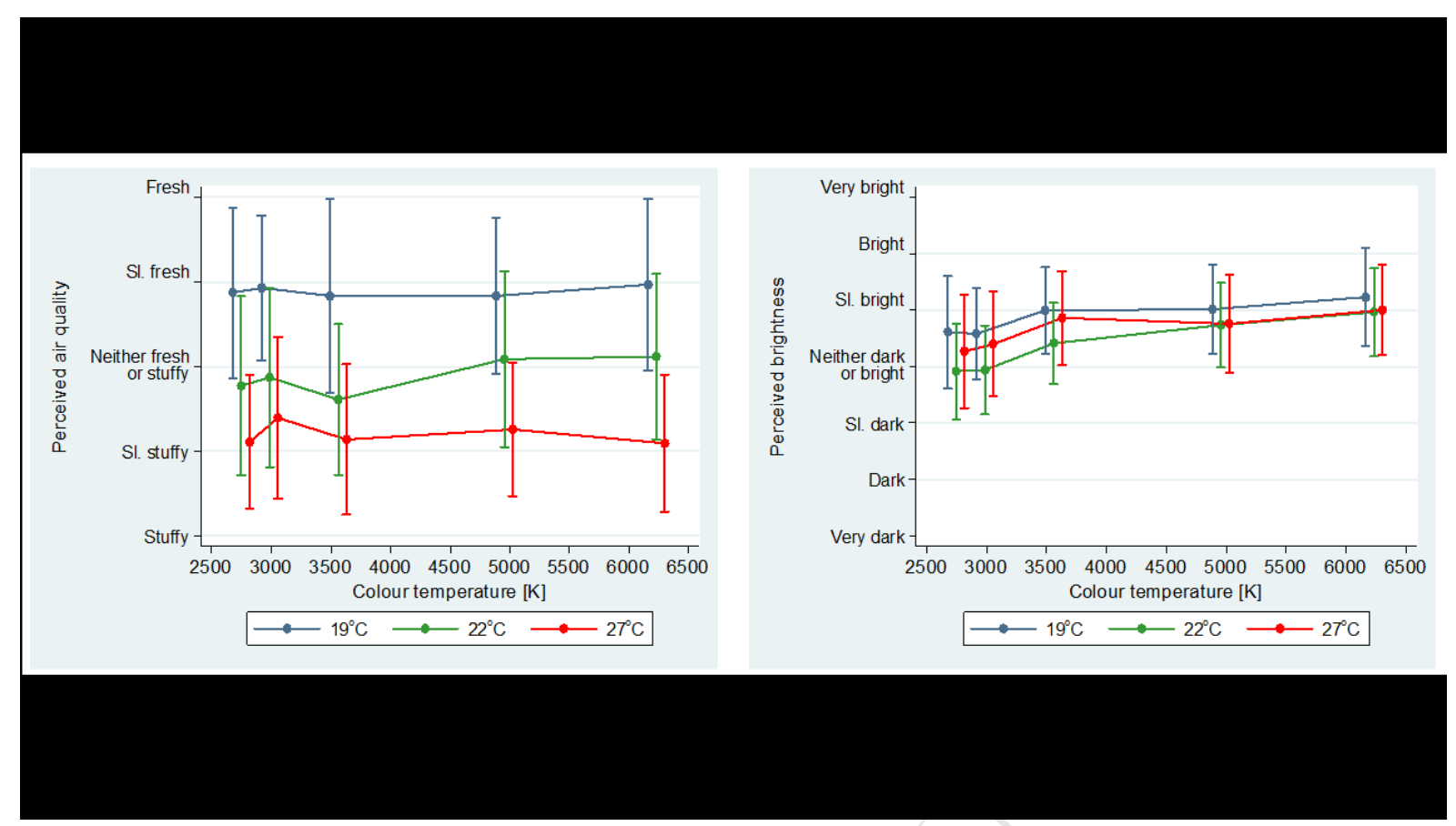


Figure captions

Figure 1. Timeline displaying the chronology of questionnaires $(Q)$ and performance tests $(P)$ during the 90 min exposure period.

Figure 2. CCT schemes used during the experiments. The values in the figure are based on measurements made after the lighting animations were set up, but prior to carrying out the experiments. The dots indicate a scene and the connecting lines indicate fades and waits.

Figure 3. Spectral distribution of the light in the test room at nominal CCTs of $2700 \mathrm{~K}, 3000 \mathrm{~K}, 3600 \mathrm{~K}$, $5000 \mathrm{~K}$, and $6300 \mathrm{~K}$.

Figure 4. Location of the lighting fixtures in the suspended ceiling and subjects' position in the test room (marked by the barrel-shaped dummies). Lines from the top of the dummies indicate the view direction.

Figure 5. Luminance distribution at the position of the second desk from left (Figure 4).

Figure 6. Comparison of nominal operative temperatures and temperatures measured in each experimental session. Top: $19^{\circ} \mathrm{C}$; middle: $22^{\circ} \mathrm{C}$; bottom: $27^{\circ} \mathrm{C}$.

Figure 7. Mean thermal sensation (left) and preference (right) as function of CCT and nominal temperature. Error bars indicate standard deviations. Abscissae shifted slightly to show error bars (jitter).

Figure 8. Mean perception of the air quality (left) and brightness of the light (right). Error bars indicate standard deviations. Abscissae shifted slightly to show error bars (jitter).

SM1. Excerpt of the applied questionnaire scales. 


\section{Highlights}

Increased correlated colour temperature significantly decreased thermal sensation at a neutral operative temperature, but not at operative temperatures on the border of the temperature comfort zone

Increased correlated colour temperature increased the perceived brightness of the light and at $22^{\circ} \mathrm{C}$ also improved the perceived air quality and caused subjects to feel more alert.

The observed shift in thermal sensation corresponded to a reduction of around $8 \%$ of a building's total annual energy use. 